\title{
Tolerância à salinidade avaliada em genótipos de arroz cultivados in vitro
}

\author{
Letícia Carvalho Benitez ${ }^{1}$, José Antonio Peters², Marcos Antonio Bacarin ${ }^{2}$, Maurício Marini Kopp ${ }^{3}$, Antonio Costa \\ de Oliveira ${ }^{4}$, Ariano Martins de Magalhães Junior ${ }^{5}$, Eugenia Jacira Bolacel Braga ${ }^{6}$
}

\section{RESUMO}

As plantas em condições naturais estão expostas a vários estresses ambientais que afetam seu metabolismo. Dentre esses, a salinidade dos solos e da água de irrigação é um dos mais sérios problemas para a agricultura irrigada. O objetivo deste trabalho foi identificar, por meio de caracteres morfológicos, a variabilidade genética de 10 genótipos de arroz, cultivados in vitro, e agrupar esses genótipos para o caráter tolerância à salinidade. Os tratamentos foram constituídos por 10 genótipos e quatro concentrações de $\mathrm{NaCl}\left(0,4,8\right.$ e $\left.12 \mathrm{mg} \mathrm{L}^{-1}\right)$ acrescidas ao meio de cultura MS. Após 21 dias, foram avaliados diversos caracteres morfológicos, para os quais foram realizados cálculos percentuais de desempenho relativo (aumento ou redução), considerando-se o valor absoluto do tratamento-controle $\left(0 \mathrm{mg} \mathrm{L}^{-1}\right)$. Todos os caracteres mensurados tiveram seu desenvolvimento reduzido em substrato salino, sendo os correspondentes à biomassa média da parte aérea e do sistema radicular os mais sensíveis ao $\mathrm{NaCl}$. Observou-se dissimilaridade entre os genótipos estudados para tolerância à salinidade, verificada pela formação de três grupos distintos pelo método hierárquico UPGMA e dois grupos pelo método de Tocher, sendo o genótipo BRS Bojuru o mais tolerante e BRS “7” Taim e BRS Ligeirinho os mais sensíveis à salinidade.

Palavras-chave: Oryza sativa L., estresse salino, dissimilaridade genética, cultivo in vitro.

\section{ABSTRACT}

\section{Salinity tolerance evaluated in genotypes of in vitro cultivated rice}

Plants under natural conditions are exposed to several environmental stresses which affect their metabolism. Among them, soil and irrigation water salinity is one of the most serious problems to irrigated agriculture. The aim of this work was to identify through morphologic characters, the genetic variability of 10 genotypes of rice cultivated in vitro, and classify these genotypes regarding salinity tolerance. The treatments were constituted by ten genotypes and four $\mathrm{NaCl}$ concentrations (0, 4, 8 and $\left.12 \mathrm{mg} \mathrm{L}^{-1}\right)$ added to MS culture medium. After 21 days, several morphological characters were evaluated, to which percentage calculations of relative performance (increase or reduction) were made, considering the absolute value of the control treatment $\left(0 \mathrm{mg} \mathrm{L}^{-1}\right)$. All the measured

Recebido para publicação em novembro de 2008 e aprovado em janeiro de 2010

${ }^{1}$ Bióloga, Mestranda. Departamento de Botânica, Universidade Federal de Pelotas, Instituto de Biologia, Campus Capão do Leão, Caixa Postal 354, 96010-900, Pelotas, Rio Grande do Sul, Brasil. leticiacbenitez@yahoo.com.br

${ }^{2}$ Engenheiros-Agrônomos, Doutores. Departamento de Botânica, Universidade Federal de Pelotas, Instituto de Biologia, Campus Capão do Leão, Caixa Postal 354, 96010-900, Pelotas, RS, Brasil. peters@ufpel.tche.br, bacarin@ufpel.tche.br

${ }^{3}$ Engenheiro-Agrônomo, Doutor. Empresa Brasileira de Pesquisa Agropecuária, Embrapa Gado de Leite.

Rua Eugênio do Nascimento, 610, Laboratório de Biotecnologia e Fisiologia Vegetal

Dom Bosco, 36038-330, Juiz de Fora, Minas Gerais, Brasil.

${ }^{4}$ Engenheiro-Agrônomo, Ph.D. Departamento de Fitotecnia, Universidade Federal de Pelotas, Campus Capão do Leão, Caixa Postal 354, 96010-900, Pelotas, RS, Brasil.acostol@terra.com.br

${ }^{5}$ Engenheiro-Agrônomo, Doutor. Empresa Brasileira de Pesquisa Agropecuária Clima Temperado, Rodovia BR 392, Km 78, Caixa Postal 403, 96001-970, Pelotas, RS, Brasil. ariano@cpact.embrapa.br

${ }^{6}$ Bióloga, Doutora. Departamento de Botânica, Universidade Federal de Pelotas, Instituto de Biologia, Campus Capão do Leão, Caixa Postal 354, 96010-900, Pelotas, RS, Brasil. Orientadora do trabalho de dissertação de mestrado do primeiro autor, Programa de Pós-Graduação em Fisiologia Vegetal. eugenia@ufpel.tche.br 
characters had their development reduced in saline substrate. The most sensitive characters to $\mathrm{NaCl}$ concentration were mean biomass from the aerial parts and from the radicular system. Differences were observed among the genotypes studied regarding salinity tolerance. Three distinct groups were formed by the UPGMA hierarchical method and two groups by Tocher method, with BRS Bojuru genotype the most tolerant and BRS"7" Taim and BRS Ligeirinho the most sensitive to salinity.

Key words: Genetic dissimilarity, in vitro cultivation, Oryza sativa L., salt stress.

\section{INTRODUÇÃO}

Cultivado e consumido em todos os continentes, o arroz destaca-se pela produção e área de cultivo, desempenhando papel estratégico tanto no aspecto econômico quanto social. Segundo dados da EMBRAPA Clima Temperado, cerca de 150 milhões de hectares de arroz são cultivados anualmente no mundo, produzindo 590 milhões de toneladas, sendo mais de $75 \%$ dessa produção oriunda do sistema de cultivo irrigado. O Brasil está entre os 10 principais produtores mundiais, com os Estados do Rio Grande do Sul, Santa Catarina e Paraná responsáveis por aproximadamente $60 \%$ da produção total desse cereal (Gomes \& Magalhães, 2004).

Assim como toda cultura agrícola, a produção de arroz é influenciada por um grande número de fatores ambientais. Alguns desses não são passíveis de manejo, como clima; enquanto outros, como solo e água, podem ser manejados para permitir o melhor desempenho da cultura. Aproximadamente $1 / 3$ dos solos do mundo apresentam altos níveis de salinidade (Liua \& Baob, 1998), tendo a salinização das águas para irrigação das lavouras da região Sul do Brasil causado danos severos à produtividade do arroz. Em função disso, a seleção e caracterização de genótipos tolerantes à salinidade tornam-se excelente alternativa para o melhoramento genético desse cereal.

O estresse salino pode inibir o crescimento das plantas, reduzindo o potencial osmótico da solução do solo, restringindo a disponibilidade da água e/ou acumulando íons em excesso nos tecidos vegetais, podendo ocasionar toxicidade iônica, desequilíbrio nutricional ou ambos (Tester \& Davenport, 2003). Nessas condições, a concentração dos íons de $\mathrm{Na}^{+}$e/ou de $\mathrm{Cl}^{-}$, frequentemente, excede as concentrações de macro e micronutrientes, reduzindo a absorção de outros nutrientes minerais, especialmente do $\mathrm{NO}_{3}^{-}, \mathrm{K}^{+}$e Ca ${ }^{2+}$ (Larcher, 2000).

$\mathrm{O}$ grau com que o estresse salino influencia o crescimento/desenvolvimento e a qualidade de produção das plantas é dependente de muitos fatores, destacando-se: a espécie vegetal, o genótipo, o estádio fenológico, a composição salina do meio, intensidade e duração do estresse, bem como as condições edafoclimáticas e o manejo de irrigação (Rhoades et al., 2000). Assim, torna-se cada vez mais importante a utilização de tecnologias que permitam identificar rapidamente genótipos com diferentes graus de tolerância ao estresse, visando sua utilização em programas de melhoramento. Uma proposta para acelerar o processo de seleção de genótipos tolerantes seria a utilização das técnicas de cultura in vitro (Andrade, 2002). Essas técnicas, além de permitirem a comparação de grande número de plantas, são também rápidas e de custo relativamente baixo, possibilitando a identificação de genótipos tolerantes antes da verificação de sua tolerância no campo (Nóbrega et al., 2004).

A determinação da dissimilaridade genética, por meio da avaliação simultânea de vários caracteres, pode ser uma ferramenta eficiente para a identificação de genótipos superiores, possibilitando a concentração de esforços nas combinações mais promissoras (Moura et al., 1999). Análises multivariadas para estudar a diversidade genética com base em caracteres morfológicos e/ou fisiológicos foram realizadas em muitas plantas, como feijão (Machado et al., 2002), Trifolium ssp. (Radomska, 2000) e fava (Terzopoulos et al., 2003).

Neste contexto, o objetivo deste trabalho foi identificar, por meio de caracteres morfológicos, a variabilidade genética de 10 genótipos de arroz, cultivados in vitro, e agrupar esses genótipos quanto ao nível de tolerância à salinidade.

\section{MATERIAL E MÉTODOS}

Para o experimento foram utilizados os genótipos BRSBojuru e Cana Roxa, pertencentes ao grupo japônica; e Talento, BRS-Atalanta, BRS-Firmeza, BRS-Pelota, BRSAgrisul, BRS-Querência, BRS-Taim e BRS-Ligeirinho, pertencentes ao grupo índica, do sistema de cultivo irrigado, procedentes da Estação Experimental Terras Baixas (Embrapa - Clima Temperado), Pelotas, Rio Grande do Sul.

Inicialmente as sementes foram desinfestadas em álcool 70\%, durante um minuto, e em solução de cloreto de mercúrio $0,05 \%$, durante três minutos, seguidas de três lavagens com água destilada, em agitação constante. Em câmara de fluxo laminar as sementes foram colocadas para 
germinar em tubos de ensaio contendo meio MS (Murashige \& Skoog, 1962) com metade da concentração de sais e suplementado com $20 \mathrm{~g} \mathrm{~L}^{-1}$ de sacarose, $100 \mathrm{mg}$ $\mathrm{L}^{-1}$ de mioinositol e solidificado com $6 \mathrm{~g} \mathrm{~L}^{-1}$ de ágar. As culturas permaneceram em câmara de crescimento durante 21 dias, com um fotoperíodo de 16 horas e densidade de fluxo de fótons de $25 \mu \mathrm{mol} \mathrm{m} \mathrm{m}^{-2}$.

Os tratamentos consistiram de 10 genótipos e quatro concentrações de $\mathrm{NaCl}$ (0, 4, 8 e $\left.12 \mathrm{mg} \mathrm{L}^{-1}\right)$ acrescidas ao meio de cultura, em delineamento experimental de blocos ao acaso, compondo um fatorial $10 \times 4$, com três repetições, cada uma delas representada por três tubos de ensaio, contendo uma semente cada. Após o preparo de cada meio ajustou-se o $\mathrm{pH}$ para 5,8, sendo distribuídos em tubos de ensaio fechados com algodão e alumínio e autoclavados a $121^{\circ} \mathrm{C}$, durante 20 minutos.

Após 21 dias em cultura, avaliaram-se a altura da parte aérea $(\mathrm{cm})$, o comprimento da raiz $(\mathrm{cm})$, número de folhas, número de raízes, e a massa fresca da parte aérea e do sistema radicular (g). Para esses caracteres foram realizados cálculos percentuais de desempenho relativo (aumento ou redução), considerando-se $100 \%$ o valor absoluto do tratamento controle $\left(0 \mathrm{mg} \mathrm{L}^{-1}\right.$ de $\left.\mathrm{NaCl}\right)$.

A partir dos dados de desempenho relativo, foi realizada análise de dissimilaridade genética entre todos os pares de genótipos por meio da distância generalizada de Mahalanobis ( $\left(\mathrm{D}^{2}\right)$, utilizando-se o programa computacional GENES (Cruz, 2001), o qual fornece, além da matriz de dissimilaridade, a contribuição relativa dos caracteres para divergência, conforme Singh (1981).

Por meio da matriz de dissimilaridade genética gerada foi aplicada a análise de agrupamento pelo método de otimização de Tocher (Cruz \& Carneiro, 2003) e construído um dendrograma pelo método de agrupamento da distância média (UPGMA). Para a estimativa do ajuste entre a matriz de dissimilaridade e o dendrograma gerado foi calculado o coeficiente de correlação cofenética (r), utilizando o programa computacional NTSYS pc 2.1 (Rohlf, 2000).

\section{RESULTADOS E DISCUSSÃO}

Baseado nos resultados referentes ao desempenho relativo dos genótipos de arroz em relação aos caracteres morfológicos analisados, observou-se que na concentração de $8 \mathrm{mg} \mathrm{L}^{-1}$ todos os caracteres tiveram redução no crescimento quando comparados ao tratamento sem adição de $\mathrm{NaCl}$ (Tabela 1). Não houve germinação das sementes de arroz na concentração de $12 \mathrm{mg} \mathrm{L}^{-1}$ de $\mathrm{NaCl}$, por isso tal tratamento não foi considerado nas análises do experimento.

Os maiores percentuais de redução relativa foram observados para a massa fresca média de raiz, 37,5 e 62,2\%, nas concentrações de 4 e $8 \mathrm{mg} \mathrm{L}^{-1}$, respectivamente, comportamento esse semelhante ao encontrado para o número médio de raiz e a massa fresca média da parte aérea, que apresentaram reduções acima de $20 \%$ na menor concentração de sal. Por outro lado, o comprimento médio de raiz teve aumento de 6,6\% na concentração de $4 \mathrm{mg} \mathrm{L}^{-1}$ e redução de 19,5\% na concentração de $8 \mathrm{mg} \mathrm{L}^{-1}$. Analisando-se os diferentes percentuais de redução relativa encontrados para cada variável analisada, pode-se concordar com Morales et al. (2001), os quais salientaram que nem todas as partes da planta são igualmente afetadas pela salinidade, bem como a adaptação ao estresse salino pode variar entre espécies e em um mesmo genótipo pode variar entre estádios fenológicos.

A redução no desenvolvimento de todos os caracteres morfológicos avaliados neste trabalho pode ser explicada de acordo com Lacerda et al. (2004), os quais afirmaram que com o aumento da salinização ocorre acúmulo de determinadas espécies iônicas, principalmente $\mathrm{Na}^{+}$e $\mathrm{Cl}^{-}$, os quais, além de causar toxidez nos tecidos vegetais, podem acarretar mudanças na capacidade da planta em absorver, transportar e utilizar os íons essenciais ao seu crescimento, como o cálcio. Os autores salientaram ainda que cereais como sorgo, milho, arroz e cevada são particularmente sensíveis à elevação de $\mathrm{Na}^{+}$e $\mathrm{Cl}^{-}$no substrato.

Tabela 1. Percentual de desempenho relativo nos caracteres morfológicos avaliados, após 21 dias, em 10 genótipos de arroz mantidos em meio MS com diferentes concentrações de $\mathrm{NaCl}$

\begin{tabular}{lccc}
\hline \multirow{2}{*}{ Caracteres morfológicos } & \multicolumn{3}{c}{ Desempenho relativo (\%) } \\
\cline { 2 - 4 } & $\mathbf{0} \mathbf{~ m g ~ L ~}^{-\mathbf{1}}$ & $\mathbf{4} \mathbf{~ m g ~ L ~}^{-\mathbf{1}}$ & $\mathbf{8} \mathbf{~ m g ~ L ~}^{-\mathbf{1}}$ \\
\hline Altura média da parte aérea (cm) & 8,56 & $-8,2 \mathrm{~A}$ & $-41,9 \mathrm{~B}$ \\
Número médio de folhas ( ${ }^{\circ}$ ) & 3,84 & $-9,6 \mathrm{~A}$ & $-16,9 \mathrm{~B}$ \\
Comprimento médio da raiz (cm) & 7,30 & $+6,6 \mathrm{~A}$ & $-19,5 \mathrm{~B}$ \\
Número médio da raiz $\left(\mathrm{n}^{\circ}\right)$ & 6,26 & $-26,5 \mathrm{~A}$ & $-49,2 \mathrm{~B}$ \\
Massa fresca média da parte aérea (g) & 0,088 & $-21,2 \mathrm{~A}$ & $-57,5 \mathrm{~B}$ \\
Massa fresca média da raiz (g) & 0,063 & $-37,5 \mathrm{~A}$ & $-62,2 \mathrm{~B}$ \\
\hline
\end{tabular}

Médias seguidas da mesma letra, nas linhas, não diferem entre si, pelo teste de Tukey, a 5\% de probabilidade de erro. (+) Aumento e (-) redução relativa, tomando como referencial o tratamento-controle (100\%). 
Tabela 2. Percentual de desempenho relativo quanto à altura média da parte aérea e ao número médio de folhas, após 21 dias, de 10 genótipos de arroz cultivados in vitro, em meio MS, acrescido de diferentes concentrações de $\mathrm{NaCl}$ quando comparados ao tratamentocontrole $\left(0 \mathrm{mg} \mathrm{L}^{-1}\right)$

\begin{tabular}{|c|c|c|c|c|c|c|}
\hline \multirow{3}{*}{ Genótipos } & \multicolumn{6}{|c|}{ Desempenho relativo (\%) } \\
\hline & \multicolumn{3}{|c|}{ Altura média da parte aérea $(\mathrm{cm})$} & \multicolumn{3}{|c|}{ Número médio de folhas } \\
\hline & $0 \mathrm{mg} \mathrm{L} \mathrm{L}^{-1 *}$ & $4 \mathrm{mg} \mathrm{L}^{-1}$ & $8 \mathrm{mg} \mathrm{L}^{-1}$ & $0 \mathrm{mg} \mathrm{L}^{-1 *}$ & $4 \mathrm{mg} \mathrm{L}^{-1}$ & $8 \mathrm{mg} \mathrm{L}^{-1}$ \\
\hline Cana Roxa & 12,87 & $-7,4$ & $-38,8$ & 3,85 & $-6,5$ & $-9,3$ \\
\hline BRS Bojuru & 9,86 & $+19,9$ & $-16,5$ & 3,89 & $-5,9$ & $-11,8$ \\
\hline BRS Firmeza & 8,66 & $-8,0$ & $-46,2$ & 3,77 & $-5,8$ & $-21,2$ \\
\hline BRS Atalanta & 8,47 & $-11,1$ & $-47,8$ & 3,43 & $-2,9$ & $-9,6$ \\
\hline BRS Talento & 8,14 & $-8,8$ & $-42,2$ & 3,42 & $-9,6$ & $-12,8$ \\
\hline BRS Querência & 8,02 & $-6,1$ & $-41,4$ & 3,99 & $-3,0$ & $-8,8$ \\
\hline BRS Pelota & 7,35 & $-3,5$ & $-35,9$ & 4,55 & $-21,9$ & $-21,9$ \\
\hline BRS Agrisul & 6,98 & $-13,6$ & $-42,8$ & 3,75 & $+0,3$ & $-8,8$ \\
\hline BRS 7 “Taim” & 8,05 & $-36,0$ & $-58,0$ & 3,49 & $-19,5$ & $-28,6$ \\
\hline BRS Ligeirinho & 7,18 & $-16,0$ & $-56,7$ & 4,33 & $-19,4$ & $-34,6$ \\
\hline
\end{tabular}

* Valor absoluto encontrado no tratamento controle. (+) Aumento e (-) redução relativa tomando como referencial o valor absoluto do tratamento-controle (100\%).

Considerando o desempenho relativo dos genótipos quanto à altura média da parte aérea, observou-se que no tratamento com $4 \mathrm{mg} \mathrm{L}^{-1}$ de $\mathrm{NaCl}$ o genótipo BRS Bojuru foi o único a apresentar aumento relativo, 19,9\%, em relação ao tratamento controle, enquanto BRS 7 "Taim" foi o que teve a maior redução, 36,0\%, nesse mesmo nível de salinidade (Tabela 2). Da mesma forma, comparando o desempenho nos níveis extremos de salinidade, 0 e $8 \mathrm{mg} \mathrm{L}^{-1}$, o genótipo BRS Bojuru foi o que apresentou a menor redução, 16,5\%, enquanto o BRS 7 “Taim” apresentou a maior, $58 \%$ (Tabela 2). A diferença de comportamento frente à salinidade encontrada entre os genótipos BRS Bojuru, pertencente ao grupo japônica, e BRS “7” Taim, pertencente ao grupo índica, corroborou os resultados constatados por Lima et al. (2005) que, ao estudarem o efeito do estresse salino em plântulas de arroz, verificaram que os cultivares japônicas apresentaram maior tolerância à salinidade para alguns caracteres morfológicos.

Reduções na altura da parte aérea de plantas de arroz sob estresse salino também foram encontradas por Rodrigues et al. (2005), os quais observaram que as plantas exploradas em ambientes mais salinos tinham porte menor que aquelas desenvolvidas em condições menos salinas, atingindo um índice de redução de 16,8\%.

Com base no desempenho relativo quanto ao número médio de folhas, observou-se que, com exceção de BRS Pelota, BRS 7 “Taim” e BRS Ligeirinho, os quais apresentaram, respectivamente, reduções de 21,9, 19,5 e 19,4\% na concentração de $4 \mathrm{mg} \mathrm{L}^{-1}$ de $\mathrm{NaCl}$, os demais genótipos mostraram reduções entre 2,9 e 9,6\%, tendo-se ainda constatado pequeno aumento de $0,3 \%$ dessa variável no genótipo BRS Agrisul (Tabela 2). Já na concentração de 8 $\mathrm{mg} \mathrm{L}^{-1}$ de $\mathrm{NaCl}$, notou-se que as menores reduções foram observadas nos genótipos BRS Agrisul, BRS Querência, Cana Roxa e BRS Atalanta, com valores de 8,8; 8,8; 9,3; e $9,6 \%$, respectivamente. Por outro lado, BRS Firmeza, BRS Pelota, BRS 7 “Taim” e BRS Ligeirinho foram os genótipos com os maiores percentuais de redução, 21,2; 21,9; 28,6;e $34,6 \%$, respectivamente (Tabela 2).

As reduções observadas no número de folhas dos genótipos analisados neste trabalho podem ser explicadas por Cavalcanti et al. (2005), os quais comentaram que, em condições de seca fisiológica, é comum ocorrerem alterações morfológicas e anatômicas nas plantas, refletindose na perda de transpiração como alternativa para manter a absorção de água, sendo uma dessas adaptações a redução do número de folhas.

Em relação aos percentuais de desempenho relativo quanto ao comprimento médio de raiz, observou-se que à medida que houve incremento da concentração salina no meio de cultura ocorreu aumento no comprimento médio de raiz na concentração de $4 \mathrm{mg} \mathrm{L}^{-1}$ em alguns genótipos, seguido de redução na concentração de $8 \mathrm{mg} \mathrm{L}^{-1}$, exceto em BRS Pelota, o qual não apresentou redução em ambas as concentrações (Tabela 3). BRS Ligeirinho, BRS Agrisul e BRS 7 “Taim” foram os únicos genótipos que apresentaram redução no comprimento médio do sistema radicular já na concentração de 4 $\mathrm{mg} \mathrm{L}^{-1}$, enquanto nos demais genótipos foram observados aumentos que variaram entre 1,2 e 36,7\%, sendo os valores extremos encontrados em Cana Roxa e BRS Bojuru (Tabela 3). Na concentração de $8 \mathrm{mg} \mathrm{L}^{-1}$, as reduções mais drásticas foram observadas em BRS Ligeirinho e BRS Taim e as menores, na BRS Atalanta (Tabela 3).

Os resultados encontrados neste trabalho estão de acordo com os relatados por Rodrigues et al. (2002), os quais, ao analisarem o efeito de diferentes níveis de salinidade da água de irrigação $\left(0,5\right.$ até $\left.8,5 \mathrm{dSm}^{-1}\right)$ em plan- 
Tabela 3. Percentual de desempenho relativo quanto ao comprimento e número médio de raízes, após 21 dias, de 10 genótipos de arroz cultivados in vitro, em meio MS, acrescido de diferentes concentrações de $\mathrm{NaCl}$ quando comparados ao tratamentocontrole $\left(0 \mathrm{mg} \mathrm{L}^{-1}\right)$

\begin{tabular}{|c|c|c|c|c|c|c|}
\hline \multirow{3}{*}{ Genótipos } & \multicolumn{6}{|c|}{ Desempenho relativo (\%) } \\
\hline & \multicolumn{3}{|c|}{ Comprimento médio de raiz $(\mathrm{cm})$} & \multicolumn{3}{|c|}{ Número médio de raízes } \\
\hline & $0 \mathrm{mg} \mathrm{L}^{-1 *}$ & $4 \mathrm{mg} \mathrm{L}^{-1}$ & $8 \mathrm{mg} \mathrm{L}^{-1}$ & $0 \mathbf{~ m g ~ L ~}^{-1 *}$ & $4 \mathrm{mg} \mathrm{L}^{-1}$ & $8 \mathrm{mg} \mathrm{L}^{-1}$ \\
\hline BRS Bojuru & 7,14 & $+36,7$ & $-6,6$ & 5,22 & $-4,6$ & $-15,1$ \\
\hline Cana Roxa & 8,38 & $+1,2$ & $-23,0$ & 7,21 & $-44,9$ & $-65,5$ \\
\hline BRS Pelota & 7,22 & $+15,5$ & $+2,3$ & 7,32 & $-29,1$ & $-48,4$ \\
\hline BRS Agrisul & 8,15 & $-10,2$ & $-14,8$ & 5,86 & $-31,2$ & $-56,6$ \\
\hline BRS Querência & 7,28 & $+8,5$ & $-14,8$ & 5,87 & $-12,1$ & $-26,6$ \\
\hline BRS Talento & 6,79 & $+12,9$ & $-21,5$ & 5,77 & $-31,9$ & $-50,2$ \\
\hline BRS 7 “Taim” & 8,10 & $-13,6$ & $-42,6$ & 7,38 & $-45,9$ & $-61,9$ \\
\hline BRS Atalanta & 5,83 & $+30,7$ & $-4,8$ & 7,33 & $-8,0$ & $-37,9$ \\
\hline BRS Ligeirinho & 7,82 & $-9,5$ & $-48,6$ & 6,55 & $-34,2$ & $-69,6$ \\
\hline BRS Firmeza & 6,27 & $+10,5$ & $-12,0$ & 4,43 & $-10,4$ & $-43,8$ \\
\hline
\end{tabular}

* Valor absoluto encontrado no tratamento-controle. (+) Aumento e (-) redução relativa tomando como referencial o valor absoluto do tratamento-controle (100\%).

tas de arroz, observaram que ao contrário de outras variáveis, o comprimento do sistema radicular só foi influenciado por valores elevados de salinidade, denotando, inclusive, tendência de maior crescimento das raízes nos tratamentos com níveis mais baixos de sal.

No que se refere ao desempenho relativo quanto ao número médio de raízes, o genótipo BRS Bojuru apresentou os menores valores de redução, com percentuais de 4,6 e 15,1\% nas concentrações de 4 e $8 \mathrm{mg} \mathrm{L}^{-1}$, respectivamente, enquanto nos genótipos BRS Ligeirinho, Cana Roxa e BRS 7 "Taim” foram encontrados os maiores percentuais de redução, equivalentes a 31,9; 44,9; e 45,9\%, respectivamente, na concentração de $4 \mathrm{mg} \mathrm{L}^{-1}$, e 69,6; 65,5; e 61,9 na concentração de $8 \mathrm{mg} \mathrm{L}^{-1}$ (Tabela 3). O excesso de sais na zona radicular das plantas pode ocasionar redução no comprimento e número de raízes, exercendo efei- tos nocivos no crescimento e desenvolvimento da planta (Rhoades et al., 2000). Para os autores, a hipótese que melhor explica esse fato é que o efeito prejudicial dos altos níveis de sal, no meio externo às raízes, acarreta diminuição na capacidade de absorção de água e nutrientes pela planta, diminuindo, consequentemente, a quantidade de nutrientes disponíveis para serem translocados aos demais órgãos, ocasionando menor crescimento e desenvolvimento do vegetal.

O desempenho relativo quanto à massa fresca média da parte aérea mostrou que os genótipos BRS Bojuru, BRS Querência, BRS Talento e BRS Atalanta apresentaram reduções inferiores a $10 \%$ na concentração de $4 \mathrm{mg}$ $\mathrm{L}^{-1}$ de $\mathrm{NaCl}$, seguidos de Cana Roxa, $12,4 \%$, na mesma concentração (Tabela 4). Para os demais genótipos foram encontradas reduções entre 20,8 e 53,0\%, sendo o

Tabela 4. Percentual de desempenho relativo quanto à massa fresca média da parte aérea e da raiz, após 21 dias, de 10 genótipos de arroz cultivados in vitro, em meio MS, acrescido de diferentes concentrações de $\mathrm{NaCl}$ quando comparados ao tratamentocontrole $\left(0 \mathrm{mg} \mathrm{L}^{-1}\right)$

\begin{tabular}{|c|c|c|c|c|c|c|}
\hline \multirow{3}{*}{ Genótipos } & \multicolumn{6}{|c|}{ Desempenho relativo (\%) } \\
\hline & \multicolumn{3}{|c|}{ Massa fresca média da parte aérea (g) } & \multicolumn{3}{|c|}{ Massa fresca média de raiz (g) } \\
\hline & $0 \mathrm{mg} \mathrm{L}^{-1 *}$ & $4 \mathrm{mg} \mathrm{L}^{-1}$ & $8 \mathrm{mg} \mathrm{L}^{-1}$ & $0 \mathrm{mg} \mathrm{L}^{-1 *}$ & $4 \mathrm{mg} \mathrm{L}^{-1}$ & $8 \mathrm{mg} \mathrm{L}^{-1}$ \\
\hline BRS Pelota & 0,1020 & $-22,0$ & $-57,8$ & 0,0713 & $-36,9$ & $-70,5$ \\
\hline BRS Bojuru & 0,0833 & $-2,0$ & $-33,2$ & 0,0630 & $-5,2$ & $-27,5$ \\
\hline BRS Agrisul & 0,0993 & $-29,2$ & $-52,4$ & 0,0733 & $-45,0$ & $-62,3$ \\
\hline BRS Querência & 0,0920 & $-8,7$ & $-58,4$ & 0,0770 & $-44,1$ & $-67,5$ \\
\hline BRS Firmeza & 0,0963 & $-20,8$ & $-57,4$ & 0,0570 & $-32,1$ & $-65,4$ \\
\hline BRS Talento & 0,0850 & $-9,0$ & $-53,4$ & 0,0470 & $-21,9$ & $-49,6$ \\
\hline Cana Roxa & 0,0863 & $-12,4$ & $-54,0$ & 0,0470 & $-36,5$ & $-50,0$ \\
\hline BRS 7 “Taim” & 0,0873 & $-42,4$ & $-53,0$ & 0,0693 & $-49,9$ & $-73,6$ \\
\hline BRS Atalanta & 0,0736 & $-9,9$ & $-68,7$ & 0,0483 & $-50,3$ & $-76,0$ \\
\hline BRS Ligeirinho & 0,0823 & $-53,0$ & $-73,3$ & 0,0516 & $-48,2$ & $-82,0$ \\
\hline
\end{tabular}

* Valor absoluto encontrado no tratamento-controle. (+) Aumento e (-) redução relativa tomando como referencial o valor absoluto do tratamento-controle $(100 \%)$. 
maior valor atribuído a BRS Ligeirinho, no tratamento com menor concentração salina. No maior nível de salinidade ( $\left.8 \mathrm{mg} \mathrm{L}^{-1}\right)$ todos os genótipos tiveram reduções bastante acentuadas quando comparados ao tratamento-controle; no entanto, BRS Bojuru foi o genótipo que teve a menor variação, com queda de $33,2 \%$ de produção de massa fresca da parte aérea, enquanto os demais apresentaram reduções acima de $50 \%$, sendo os maiores valores encontrados para BRS Ligeirinho, BRS Atalanta e BRS 7 “Taim”, com 73,3; 68,7; e 68,3\% de redução, respectivamente.

Em relação ao percentual de desempenho relativo quanto à massa fresca média de raiz (Tabela 4), notou-se que na concentração de $4 \mathrm{mg} \mathrm{L}^{-1}$, com exceção de BRS Bojuru e BRS Talento, os genótipos já apresentaram reduções superiores a $30 \%$. Na concentração de $8 \mathrm{mg} \mathrm{L}^{-1}$, todos os genótipos foram altamente sensíveis, demonstrando ser essa concentração, bastante prejudicial às plantas de arroz no que concerne à produção média de raiz. O genótipo BRS Bojuru teve a menor redução observada em $8 \mathrm{mg} \mathrm{L}^{-1}$ $(27,5 \%$,$) , enquanto a maior foi encontrada em BRS$ Ligeirinho (82,0\%). Os demais genótipos mostraram reduções que variaram de 49,6 a 76,0\% nessa mesma concentração, demonstrando, assim, o efeito prejudicial da salinidade no sistema radicular.

Na análise para verificar a contribuição relativa de cada variável para a dissimilaridade genética, obtida por meio da técnica multivariada de quantificação da distância de Mahalanobis, observou-se que a massa fresca da raiz e da parte aérea foram os caracteres morfológicos que mais contribuíram para a divergência entre os genótipos (Tabela 5). Esse resultado destaca a importância desses para estudos de dissimilaridade cujo objetivo seja verificar a tolerância de genótipos de arroz submetidos à salinidade e cultivados in vitro.

Pelo método de Singh (1981), consideram-se de menor importância os caracteres que apresentam menor variabilidade. Assim, nesse trabalho os caracteres que menos contribuíram para diferenciar os genótipos foram número de folhas e altura da parte aérea (Tabela 5).

Por meio da matriz de dissimilaridade, baseada na distância de Mahalanobis $\left(\mathrm{D}^{2}\right)$, foram caracterizados como genótipos mais similares BRS Firmeza e BRS Pelota $\left(\mathrm{D}^{2}=\right.$ 1,40), pertencentes ao grupo índica (Tabela 6). Tais genótipos apresentaram percentual de desempenho relativo semelhante nos caracteres que mais contribuíram para a divergência genética, justificando a sua proximidade. Os genótipos mais dissimilares foram BRS Bojuru e BRS Ligeirinho $\left(D^{2}=96,87\right)$, sendo o primeiro pertencente ao grupo japônica e o segundo, ao índica (Tabela 6). Em relação ao desempenho relativo de cada um desses genótipos para a massa fresca média da parte aérea e massa fresca média de raiz, observou-se, claramente, o comportamento contrastante desses genótipos. $\mathrm{O}$ fato

Tabela 5. Percentual de contribuição relativa dos caracteres morfológicos quanto à divergência genética (S.j) de 10 genótipos de arroz cultivados in vitro, em meio MS, acrescido de diferentes concentrações de $\mathrm{NaCl}$

\begin{tabular}{lcc}
\hline Caracteres morfológicos & $\mathbf{S . j}$ & Contribuição relativa (\%) \\
\hline Altura da parte aérea & 51,035947 & 6,0812 \\
Número de folhas & 5,315657 & 0,6334 \\
Comprimento de raiz & 138,958365 & 16,5575 \\
Número de raiz & 146,170713 & 17,4169 \\
Massa fresca da parte aérea & 214,914556 & 25,6081 \\
Massa fresca de raiz & 282,849952 & 33,7029 \\
\hline
\end{tabular}

Tabela 6. Matriz de dissimilaridade com base na distância de Mahalanobis $\left(\mathrm{D}^{2}\right)$ entre 10 genótipos de arroz cultivados in vitro, em meio MS, acrescido de diferentes concentrações de $\mathrm{NaCl}$

\begin{tabular}{|c|c|c|c|c|c|c|c|c|c|c|}
\hline Genótipos $^{1}$ & 1 & 2 & 3 & 4 & 5 & 6 & 7 & 8 & 9 & 10 \\
\hline 1 & 0 & & & & & & & & & \\
\hline 2 & 21,93 & 0 & & & & & & & & \\
\hline 3 & 41,81 & 10,44 & 0 & & & & & & & \\
\hline 4 & 30,70 & 3,82 & 2,72 & 0 & & & & & & \\
\hline 5 & 34,52 & 5,20 & 3,21 & 1,40 & 0 & & & & & \\
\hline 6 & 40,77 & 3,56 & 10,41 & 6,01 & 5,44 & 0 & & & & \\
\hline 7 & 50,96 & 7,92 & 6,02 & 4,19 & 4,67 & 2,86 & 0 & & & \\
\hline 8 & 33,74 & 6,23 & 2,50 & 2,11 & 3,99 & 6,87 & 4,86 & 0 & & \\
\hline 9 & 89,21 & 25,88 & 19,06 & 17,07 & 16,72 & 15,50 & 7,63 & 20,62 & 0 & \\
\hline 10 & 96,87 & 34,43 & 25,34 & 22,35 & 21,60 & 24,02 & 13,28 & 28,10 & 2,49 & 0 \\
\hline
\end{tabular}

${ }^{1}$ BRS Bojuru (1); BRS Talento (2); BRS Atalanta (3); BRS Firmeza (4); BRS Pelota (5); Cana Roxa (6); BRS Agrisul (7); BRS Querência (8); e BRS 7 "Taim” (9); BRS Ligeirinho (10). 


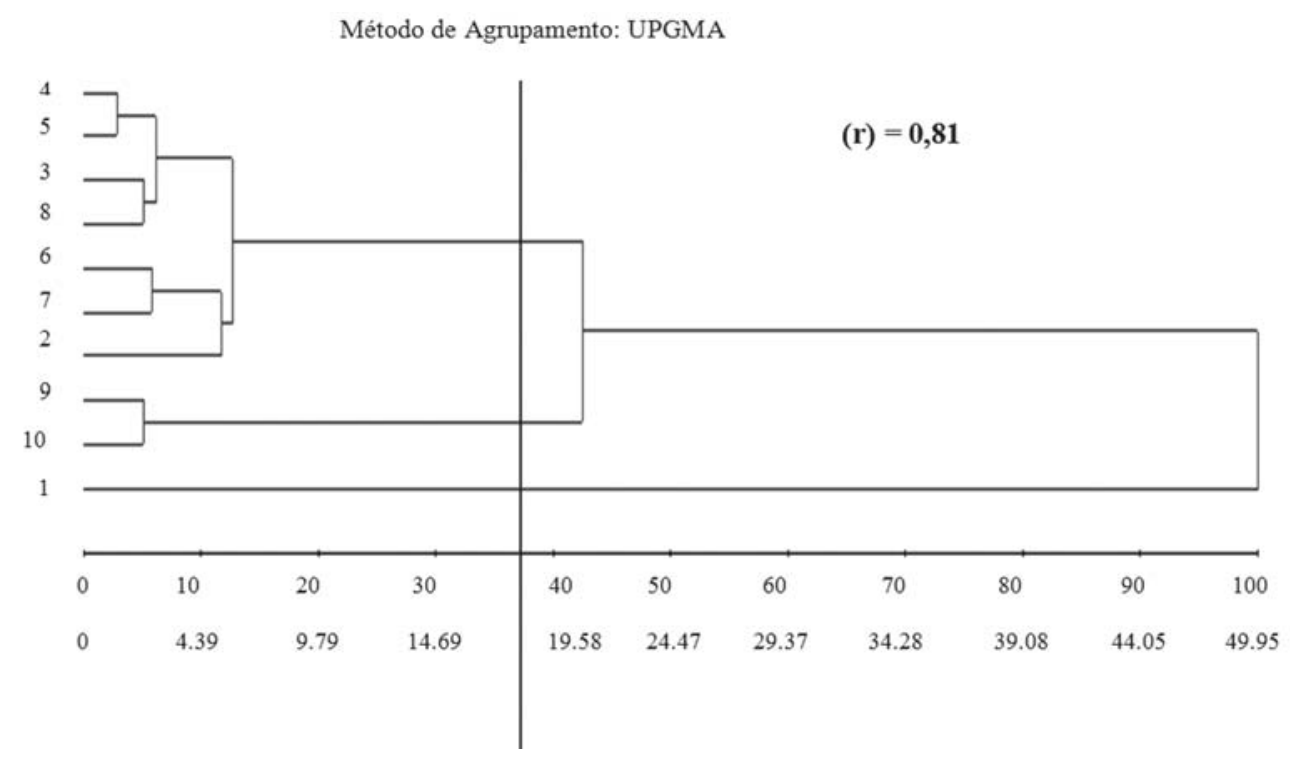

Figura 1. Dendrograma resultante da análise de agrupamento de 10 genótipos de arroz cultivados in vitro, em meio MS, acrescido de 0, 4 e $8 \mathrm{mg} \mathrm{L}^{-1}$ de $\mathrm{NaCl}$, pelo método UPGMA, obtido a partir da distância de Mahalanobis baseada em caracteres morfológicos. BRS Bojuru (1); BRS Talento (2); BRS Atalanta (3); BRS Firmeza (4); BRS Pelota (5); Cana Roxa (6); BRS Agrisul (7); BRS Querência (8); BRS 7 “Taim” (9); e BRS Ligeirinho (10).

deles pertencerem a grupos diferentes e as respostas distintas frente ao estresse poderia justificar a alta dissimilaridade entre eles.

Segundo Rodrigues et al. (2005), para determinar quão distante geneticamente uma população (ou genótipo) é de outra, são utilizados métodos biométricos, em que se quantifica ou estima a heterose, que são analisados pela estatística multivariada, permitindo unificar múltiplas informações de um conjunto de caracteres. No presente trabalho, a análise de agrupamento pelo método hierárquico UPGMA permitiu a formação de um dendrograma em que os genótipos foram agrupados em três grupos distintos, cuja dissimilaridade média entre eles foi de 18,65 (Figura 1).

O genótipo BRS Bojuru (1) foi o mais distante em relação aos demais, ficando em um grupo isolado (grupo 3). Esse genótipo foi o que apresentou as menores médias de redução relativa para a maioria dos caracteres morfológicos avaliados, demonstrando comportamento diferenciado frente ao estresse a que foi submetido. Os genótipos BRS 7 “Taim” (9) e BRS Ligeirinho (10) foram inseridos no mesmo grupo (grupo 2). Ambos per-

Tabela 7. Agrupamento baseado em caracteres morfológicos, pelo método de Tocher, de 10 genótipos de arroz cultivados in vitro, em meio MS, acrescido de 0 , 4 e $8 \mathrm{mg} \mathrm{L}^{-1}$ de $\mathrm{NaCl}$

\begin{tabular}{|c|c|}
\hline Grupos & Genótipos $^{1}$ \\
\hline 1 & $4,5,3,8,7,6,2,9,10$ \\
\hline 2 & 1 \\
\hline
\end{tabular}

tencem ao grupo índica e apresentaram comportamento semelhante frente à salinidade nos caracteres que mais contribuíram para a divergência entre os genótipos, sendo a distância encontrada entre eles de $D^{2}=2,49$ (Figura 1).

O grupo 1 abrangeu sete genótipos, BRS Talento (2), BRS Agrisul (7), Cana Roxa (6), BRS Querência (8), BRS Atalanta (3), BRS Pelota (5) e BRS Firmeza (4). Dentre estes, BRS Firmeza (4) e BRS Pelota (5) foram os que apresentaram a menor dissimilaridade, $\mathrm{D}^{2}=1,40$, seguidos de BRS Atalanta e BRS Querência, cuja dissimilaridade foi de $\mathrm{D}^{2}=2,50$, e de Cana Roxa (6) e BRS Agrisul (7), os quais apresentam $\mathrm{D}^{2}=2,86$, indicando que estes pares de genótipos responderam de maneira semelhante ao estresse (Figura 1). A correlação cofenética (r) foi de 0,81 , mostrando que esse dendrograma representa $81 \%$ da matriz de Mahalanobis.

O método de agrupamento de otimização de Tocher identifica, a partir da matriz de dissimilaridade, o par de indivíduos mais similares que formarão o primeiro grupo. A partir daí será avaliada a possibilidade de inclusão de novos indivíduos, adotando-se como critério de que a distância média intragrupo deve ser menor que a distância média intergrupo (Cruz \& Carneiro, 2006). Esse método permitiu o agrupamento dos genótipos de arroz em apenas dois grupos, sendo o grupo 2 formado pelo genótipo BRS-Bojuru e o grupo 1 pelos demais genótipos (Tabela 7).

Pesquisas envolvendo caracteres morfológicos devem ser repetidas e associadas a análises moleculares para avaliar a adaptabilidade de novas constituições genéticas introduzidas no sistema produtivo. 


\section{CONCLUSÕES}

Com base nos resultados observados pelos cálculos de desempenho relativo dos caracteres morfológicos em 10 genótipos de arroz, cultivados in vitro e agrupados quanto ao nível de tolerância à salinidade, conclui-se que: o método UPGMA é o que melhor agrupa os genótipos, o BRS Bojuru é o genótipo que se mostra mais tolerante, enquanto BRS 7 “Taim” e BRS Ligeirinho são os mais sensíveis à salinidade.

\section{REFERÊNCIAS BIBLIOGRÁFICAS}

Andrade SR (2002) Princípios da cultura de tecidos vegetais. Planaltina, Documentos/EMBRAPA CERRADOS. 58p.

Cavalcanti MLF, Fernandes PD, Hans RG, Barros GJ, Soares FAL \& Siqueira EC (2005) Tolerância da mamoneira BRS 149 à salinidade: germinação e características de crescimento. Revista Brasileira de Engenharia Agrícola e Ambiental, 9:57-61.

Cruz CD (2001) Programa Genes: Aplicativo computacional em genética e estatística. Viçosa, Editora da UFV.

Cruz CD \& Carneiro PCS (2003) Modelos biométricos aplicados ao melhoramento genético. Viçosa, Editora da UFV. 585p.

Cruz CD \& Carneiro PCS (2006) Modelos biométricos aplicados ao melhoramento genético, v. 2. Viçosa, Editora da UFV. 585p.

Gomes A da S \& Magalhães AM de (2004) Arroz irrigado no sul do Brasil. Brasília, Embrapa Informação Tecnológica. 899p.

Lacerda CF, Cambraia J, Oliva MA \& Ruiz HA (2004) Influência do cálcio sobre o crescimento e soluto em plantas de sorgo estressadas com cloreto de sódio. Revista Brasileira de Ciências do Solo, 28:289-295.

Larcher W (2000) Ecofisiologia vegetal. São Carlos, Rima Artes e Textos. 531p.

Lima MGS, Fernandes NL, Moraes DM \& Abreu CM (2005) Qualidade fisiológica de sementes de arroz submetidas à estresse salino. Revista Brasileira de Sementes, 27:54-61.

Liua P \& Baob W (1998) Cell types in the wild type of rice (Oryza sativa L.) as revealed by screening for salt tolerant lines with selection pressure. Plant Science, 131:195-202.

Machado CF, Nunes GHS, Ferreira DF \& Santos JB (2002) Divergência genética entre genótipos de feijoeiro a partir de técnicas multivariadas. Ciência Rural, 32:251-258.

Morales MA, Olmos E, Torrecillas A \& Alarcon JJ (2001) Differences in water relations, leaf ion accumulation and excretion rates between cultivated and wild species of Limonium sp. grown in conditions of saline stress. Flora, 196:345-352.

Moura WM, Casali VWD \& Cruz CD (1999) Divergência genética em linhagens de pimentão em relação à eficiência nutricional de fósforo. Pesquisa Agropecuária Brasileira, 34:217-224.

Murashige T \& Skoog F (1962) A revised medium for rapid growth and bioassays with tabacco tissue culture. Physiologia Plantarum, 15:473-497.

Nóbrega RSA, Motta JS, Lacerda AM \& Moreira FMS (2004) Tolerância de bactérias diazotróficas simbióticas à salinidade in vitro. Ciência e Agrotecnologia, 28:899-905.

Radomska ZB (2000) Morphological relationships among 15 species of Trifolium occurring in Poland. Genetic Resource and Crop Evolution, 47:267-272.
Rhoades JD, Kandiah A \& Mashali AM (2000) Uso de águas salinas para a produção agrícola. In: Gheyi HR, Sousa JR \& Queiroz JE (Eds.) Estudos FAO de irrigação e drenagem. Campina Grande, UFPB. p.40-48.

Rodrigues LN, Fernandes PD, Hans RG \& Viana SB (2002) Germinação e formação de mudas de arroz irrigado sob estresse salino. Revista Brasileira de Engenharia Agrícola e Ambiental, 6:397-403.

Rodrigues LN, Fernandes PD, Hans RG, Aparecida RN \& Correia KG (2005) Produção de arroz em condições de salinidade a partir de mudas formadas com e sem estresse salino. Revista Brasileira de Engenharia Agrícola e Ambiental, 9:95-100.

Rohlf FJ (2000) Numerical taxonomy and multivariate analysis system. Port Jefferson, Apllied Bioestatistics.

Sing D (1981) The relative importance of characters affecting genetic divergence. The Indian Journal of Genetic and Plant Breeding, 36:237-245.

Terzopoulos PJ, Kaltsikes PJ \& Bebeli PJ (2003) Collection, evaluation and classification of Greek populations of faba bean (Vicia faba L.). Genetic Resources and Crop Evolution, 50:373-381.

Tester M \& Davenport R (2003) Na+ tolerance and Na+ transport in higher plants. Annals of Botany, 91:503-527. 